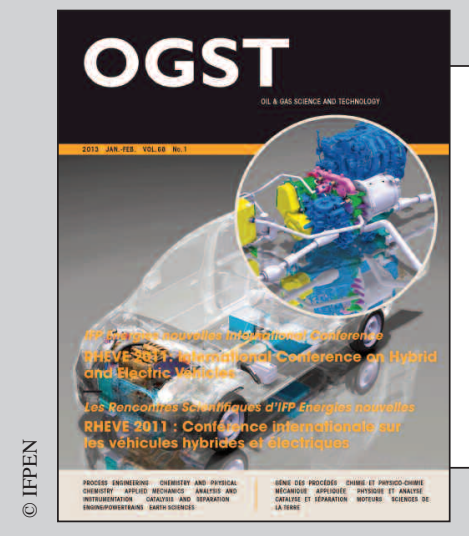

Dossier

This paper is a part of the hereunder thematic dossier published in OGST Journal, Vol. 68, No. 1, pp. 3-178 and available online here

Cet article fait partie du dossier thématique ci-dessous publié dans la revue OGST, Vol. 68, n 1 , pp. 3-178 et téléchargeable ici

DOSSIER Edited by/Sous la direction de : A. Sciarretta, F. Badin et J. Bernard RHEVE 2011 : International Conference on Hybrid and Electric Vehicles RHEVE 2011 : Conférence internationale sur les véhicules hybrides et électriques

Oil \& Gas Science and Technology - Rev. IFP Energies nouvelles, Vol. 68 (2013), No. 1, pp. 3-178

Copyright (C) 2013, IFP Energies nouvelles

\section{$3>$ Editorial}

$13>$ Analysis and Experimental Implementation of a Heuristic Strategy for Onboard Energy Management of a Hybrid Solar Vehicle

Analyse et expérimentation d'une stratégie heuristique pour la gestion d'énergie à bord d'un véhicule hybride solaire

G. Coraggio, C. Pisanti, G. Rizzo and M. Sorrentino

23 > Open Issues in Supervisory Control of Hybrid Electric Vehicles: A Unified Approach Using Optimal Control Methods

Questions ouvertes sur la supervision énergétique des véhicules hybrides électriques : une approche unifiée par la théorie de la commande optimale

L. Serrao, A. Sciarretta, 0. Grondin, A. Chasse, Y. Creff, D. Di Domenico, P. Pognant-Gros, C. Querel and L. Thibault

35 > Optimization of Hybrid Power Trains by Mechanistic System Simulations

Optimisation de groupes motopropulseurs électriques hybrides par simulation du système mécanique

T. Katrašnik and J.C. Wurzenberger

51 > A Phenomenological Heat Transfer Model of SI Engines - Application to the Simulation of a Full-Hybrid Vehicle

Un modèle phénoménologique de transfert thermique au sein de moteurs à allumage commandé - Application à la simulation d'un véhicule full-hybride

R. Dubouil, J.-F. Hetet and A. Maiboom

$65>$ Battery Electric Vehicle (BEV) or Range Extended Electric Vehicle (REEV)? - Deciding Between Different Alternative Drives Based on Measured Individual Operational Profiles

Véhicule électrique à batteries (BEV) ou véhicule électrique à prolongateur d'autonomie (REEV) ? - Choisir entre différents entrânements alternatifs sur la base de profils opérationnels individuels mesurés

S. Marker, B. Rippel, P. Waldowski, A. Schulz and V. Schindler

$79>$ Assessment by Simulation of Benefi ts of New HEV Powertrain Configurations

Évaluation par simulation des bénéfi ces de nouvelles chaînes de traction hybrides

N. Kim and A. Rousseau
95 > Dual Mode Vehicle with In-Wheel Motor: Regenerative Braking Optimization

Véhicule bi-mode avec moteurs roues : optimisation du freinage récupératif

G. Le Solliec, A. Chasse, J. Van-Frank and D. Walser

109 > Engine Downsizing and Electric Hybridization Under Consideration of Cost and Drivability

Réduction de taille moteur et hybridation électrique avec considérations de coût et de performance de conduite

S. Ebbesen, P. Elbert and L. Guzzella

117 > Representative Midwestern US Cycles: Synthesis and Applications Cycles représentatifs du Middle West américain : synthèse et applications

T.-K. Lee and Z.S. Filipi

127 > A Review of Approaches for the Design of Li-lon BMS Estimation Functions

Revue de différentes approches pour l'estimation de l'état de charge de batteries Li-ion

D. Di Domenico, Y. Creff, E. Prada, P. Duchêne, J. Bernard and V. Sauvant-Moynot

137 > Experimental Assessment of Battery Cycle Life Within the SIMSTOCK Research Program

Évaluation expérimentale de la durée de vie de la batterie dans le programme de recherche SIMSTOCK

P. Gyan, P. Aubret, J. Hafsaoui, F. Sellier, S. Bourlot, S. Zinola and F. Badin

$149>$ Smart Battery Thermal Management for PHEV Efficiency Une gestion avancée de la thermique de la batterie basse tension de traction pour optimiser l'efficacité d'un véhicule hybride électrique rechargeable

L. Lefebvre

$165>$ Parameterization and Observability Analysis of Scalable Battery Clusters for Onboard Thermal Management

Paramétrage et analyse d'observabilité de clusters de batteries de taille variable pour une gestion thermique embarquée

Xinfan Lin, Huan Fu, Hector E. Perez, Jason B. Siege, Anna G. Stefanopoulou, Yi Ding and Matthew P. Castanier 


\title{
Parameterization and Observability Analysis of Scalable Battery Clusters for Onboard Thermal Management
}

\author{
Xinfan Lin ${ }^{1 *}$, Huan Fu ${ }^{1}$, Hector E. Perez ${ }^{1}$, Jason B. Siege ${ }^{1}$, Anna G. Stefanopoulou' ${ }^{1}$ Yi Ding ${ }^{2}$ \\ and Matthew P. Castanier ${ }^{2}$ \\ 1 Department of Mechanical Engineering, University of Michigan, Ann Arbor, Michigan, 48109 - USA \\ 2 U.S. Army Tank Automotive Research, Development and Engineering Center (TARDEC), Warren, Michigan, 48397 - USA \\ e-mail: xflin@umich.edu - fuhuan@umich.edu - heperez@umich.edu - siegelib@umich.edu - annastef@umich.edu - \\ yi.ding@us.army.mil-matt.castanier@us.army.mil \\ * Corresponding author,
}

Résumé - Paramétrage et analyse d'observabilité de clusters de batteries de taille variable pour une gestion thermique embarquée - Bien que la température de surface d'une batterie soit généralement mesurée, la température interne d'une cellule peut être beaucoup plus élevée donc plus critique que la température de surface. La température interne d'une batterie, pourtant normalement non mesurée dans les applications commerciales, peut être évaluée par un observateur, sur la base d'un modèle thermique de batterie à constantes localisées et à partir de la mesure du courant et de la température de surface. Même avec un observateur en boucle fermée basé sur la température de surface mesurée, la précision de l'estimation de la température interne dépend des constantes du modèle. Dans cette optique, une méthodologie de paramétrage en ligne et un observateur adaptatif sont conçus pour une batterie cylindrique. Le modèle thermique à une seule cellule est ensuite agrandi afin de créer un modèle de cluster de batteries dans le but d'étudier le schéma de température du cluster. Les interconnexions thermiques modélisées entre les cellules incluent la conduction de chaleur de cellule à cellule et la convection au flux du liquide de refroidissement environnant. Une analyse d'observabilité est effectuée sur le cluster avant la conception, pour le pack, d'un observateur en boucle fermée. Sur la base de l'analyse, les lignes directrices permettant la détermination du nombre minimal de sondes requises et leurs positionnements exacts sont déduites permettant d'assurer l'observabilité de tous les états thermiques.

\footnotetext{
Abstract - Parameterization and Observability Analysis of Scalable Battery Clusters for Onboard Thermal Management - Although the battery surface temperature is commonly measured, the core temperature of a cell may be much higher hence more critical than the surface temperature. The core temperature of a battery, though usually unmeasured in commercial applications, can be estimated by an observer, based on a lumped-parameter battery thermal model and the measurement of the current and the surface temperature. Even with a closed loop observer based on the measured surface temperature, the accuracy of the core temperature estimation depends on the model parameters. For such purpose, an online parameterization methodology and an adaptive observer are designed for a cylindrical battery. The single cell thermal model is then scaled up to create a battery cluster model to investigate the temperature pattern of the cluster. The modeled thermal interconnections between cells include cell to cell heat conduction and convection to the surrounding coolant flow. An observability
} 
analysis is performed on the cluster before designing a closed loop observer for the pack. Based on the analysis, guidelines for determining the minimum number of required sensors and their exact locations are derived that guarantee the observability of all temperature states.

\section{INTRODUCTION}

Lithium-Ion (Li-ion) batteries are attractive energy storage devices for many portable systems and Hybrid Electric Vehicles (HEV) due to their high specific power and energy density compared with other batteries such as NiMH and lead acid. However, they typically have a constrained window of operating temperatures, around -10 to $50^{\circ} \mathrm{C}$. This constraint poses a unique cooling challenge for vehicles that operate in a very wide temperature range of -46 to $72^{\circ} \mathrm{C}$ or have cooling limitations due to volume or weight constraints, such as robots and armored vehicles.

When batteries are operated outside their nominal temperature range, e.g. during overheating or operating in elevated temperatures, their lifespan and storage capacity are reduced and performance degrades [1]. An accurate prediction of battery thermal dynamics is the key to effective thermal management, and hence safety, performance and longevity of these Li-ion batteries [2].

Thermal modeling and management of batteries have received considerable attention in the past [3-9]. Some of those works model detailed temperature distribution throughout the cell $[4,5,7,9]$ but they are generally computationally intensive and thus not suitable for onboard battery thermal management. Some of them use one single temperature to capture the lumped thermal behavior of the cell $[3,4,6,8]$ under certain conditions. However, the temperature in the core of the cell can be much higher than in the surface [10], especially when the battery is operating under high C-rate. Since direct measurement of the temperature can only be performed on the surface of the cell, a battery thermal model is needed for estimating the battery core temperature $T_{c}$ based on the measurement of the surface temperature $T_{s}$.

A second order lumped thermal model for cylindrical lithium ion batteries have been proposed in [11]. Such simplified model captures both the surface and core temperatures of the cell, and is efficient enough for onboard application. In order for the observer to work well, the model parameters should be as accurate as possible. Since all these parameters are lumped parameters, textbook values found by correlating to the geometry of the battery and physical properties of all its components [11] may not be accurate. The parameters can also be determined based on data obtained from designed experiments with extra measurements in a offline fashion [10,11]. However, there could be two major disadvantages with this technique. First, since the parameters are usually geometry and chemistry dependent, every time the model is applied to a new type of battery, new experiments will have to be designed and conducted for parameterization. Second, some of the critical parameters, such as the internal resistance, may change over battery lifetime due to degradation, and thus should be identified continuously.

In order to address such problems, an online parameter identification scheme is designed in this paper. It can automatically identify the thermal model parameters without human intervention, based on the current and surface temperature of the battery, which are the commonly measured signals in a vehicle battery management system. It is shown here that the current of real drive cycles is sufficient for the identification. An adaptive observer is then designed using the identified parameters for temperature estimation. The online identification scheme is capable of tracking the varying parameters, either by resetting itself periodically over the battery lifetime or by using forgetting factors [12]. Consequently, the scheme can not only ensure that the temperature estimation will not be affected by parameter drift but also detect the degradation by identifying the growth in internal resistance.

Applications such as HEV's usually have hundreds, or even thousands, of battery cells in series and in parallel to meet their high power and voltage requirements. The cells are usually clustered in modules with specific electric and thermal connections. The temperatures for cells in a pack can vary significantly $[2,6]$, due to pack geometry, cooling conditions among other factors. As a result, it is desirable to monitor the temperatures of all the cells in the pack but this is not economically feasible. Therefore, a thermal model for the battery cluster is developed in this paper by scaling up the single cell model considering the effect of thermal interconnections between cells. Based on the thermal model, an observer is designed to estimate all the core and surface temperatures with the knowledge of the measured input current, coolant flow rate, coolant inlet temperature, and strategically placed surface temperature measurements. Finally a sensor deployment strategy based on the observability conditions of the pack model is developed and the minimum number of required sensors can be investigated.

\section{LUMPED THERMAL MODEL OF A CYLINDRICAL LITHIUM-ION BATTERY}

A cylindrical battery is modeled with two states, one for the surface temperature $T_{s}$ and the other for the core temperature $T_{c}$, as shown in Figure 1 (adopted from [11]). 


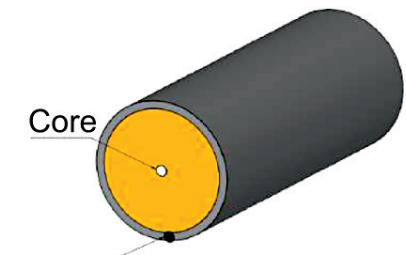

Surface

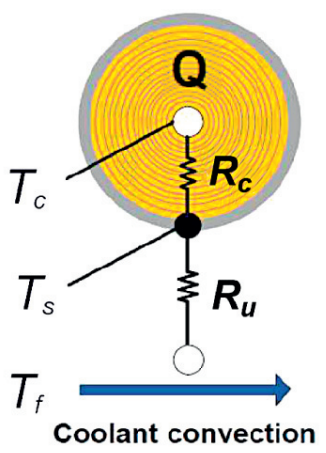

Figure 1

Single cell lumped resistance thermal model.

The governing equations for the single cell thermal model are defined as in [11]:

$$
\begin{aligned}
& C_{c} \frac{d T_{c}}{d t}=I^{2} R_{e}+\frac{T_{s}-T_{c}}{R_{c}} \\
& C_{s} \frac{d T_{s}}{d t}=\frac{T_{f}-T_{s}}{R_{u}}-\frac{T_{s}-T_{c}}{R_{c}}
\end{aligned}
$$

In this model, heat generation is approximated as a concentrated Joule loss in the battery core based on the simplified structure, computed as the product of the current, $I$, squared and the internal resistance, $R_{e}$. In general, $R_{e}$ is both temperature and State of Charge (SOC) dependent and different for charging and discharging. For simplicity, it is here considered as a constant. The more complicated varying $R_{e}$ is addressed in another publication [12].

Heat exchange between the core and the surface is modeled by heat conduction over a thermal resistance, $R_{c}$, which is a lumped parameter including both the conduction and contact thermal resistance. A convection resistance $R_{u}$ is modeled between the surface and the surrounding coolant to account for convective cooling. The coolant temperature is denoted as $T_{f}$. The convection resistance $R_{u}$ is actually a nonlinear function of the flow rate of the surrounding coolant. In some vehicle battery systems, the coolant flow rate is adjusted to control the battery temperature. Here, it is considered as a constant for simplicity. A model with the more complicated varying $R_{u}$ has also been investigated in [12]. The rates of temperature change of the surface and the core depend on their respective lumped heat capacities $C_{s}$ and $C_{c}$, where $C_{c}$ is the heat capacity of the jelly roll inside the cell and $C_{s}$ is the heat capacity of the battery casing.

The complete parameter set for the model in Equation (1) includes $C_{c}, C_{s}, R_{e}, R_{c}$ and $R_{u}$. Model identification techniques are developed in the following section to obtain parameter values based on measurable inputs and outputs.

\section{PARAMETERIZATION METHODOLOGY}

For linear model identification, a parametric model:

$$
z=\theta^{T} \phi
$$

should be derived first by applying Laplace transformation to the model, where $z$ is the observation, $\theta$ is the parameter vector and $\phi$ is the regressor [13]. Both $z$ and $\phi$ should be measured signals.

With a parametric model available, various algorithms can be chosen for parameter identification, such as the gradient and the least squares methods. The least squares algorithm is preferred here due to its advantages in noise reduction [13], which can be applied in either a recursive or a non-recursive form.

The non-recursive least squares is performed offline using all of the experimental data over a time period $t_{1}, t_{2}, \ldots, t$. The parameters can be calculated by [13]:

$$
\theta(t)=\left(\phi^{T}(t) \phi(t)\right)^{-1} \phi(t) Z(t)
$$

where:

$$
\begin{aligned}
& Z(t)=\left[\begin{array}{llll}
\frac{z\left(t_{1}\right)}{m\left(t_{1}\right)} & \frac{z\left(t_{2}\right)}{m\left(t_{2}\right)} & \ldots & \frac{z(t)}{m(t)}
\end{array}\right]^{T} \\
& \phi(t)=\left[\begin{array}{llll}
\frac{\phi^{T}\left(t_{1}\right)}{m\left(t_{1}\right)} & \frac{\phi^{T}\left(t_{2}\right)}{m\left(t_{2}\right)} & \ldots & \frac{\phi^{T}(t)}{m(t)}
\end{array}\right]^{T} \\
& m(t)=\sqrt{1+\phi^{T}(t) \phi(t)}
\end{aligned}
$$

The normalization factor $m(t)$ is used to enhance the robustness of parameter identification.

The recursive least squares algorithm is applied in an online fashion [13], as parameters are updated at each time step by:

$$
\begin{aligned}
\dot{\theta}(t) & =P(t) \frac{\epsilon(t) \phi(t)}{m^{2}(t)} \\
\dot{P}(t) & =-P(t) \frac{\phi(t) \phi^{T}(t)}{m^{2}(t)} P(t) \\
\epsilon(t) & =z(t)-\theta^{T}(t) \phi(t) \\
m^{2}(t) & =1+\phi^{T}(t) \phi(t)
\end{aligned}
$$

where $P$ is the covariance matrix and $\epsilon$ is the error in observation.

If the observation $z$ and the regressors $\phi$ in Equation (2) are not proper or causal, i.e., the order of the denominator is lower than that of the numerator, a filter $1 / \Lambda(s)$ will have to be designed and applied to each signal to make it proper. The parametric model will then become:

$$
\frac{1}{\Lambda}(s) z=\frac{1}{\Lambda}(s) \theta^{T} \phi
$$




\section{PARAMETERIZATION OF THE CYLINDRICAL BATTERY THERMAL MODEL}

In this section, the parameterization scheme described previously is applied to the cylindrical battery thermal model. According to Equation (1), the inputs of the model are the current $I$ and the coolant temperature $T_{f}$, and the measurable output is the battery surface temperature $T_{s}$. A parametric model for identification can be derived from Equation (1) by performing Laplace transformation and substituting the unmeasured $T_{c}$ by measurable $I, T_{f}$ and $T_{s}$ :

$$
\begin{aligned}
s^{2} T_{s}-s T_{s, 0}= & \frac{R_{e}}{C_{c} C_{s} R_{c}} I^{2}+\frac{1}{C_{c} C_{s} R_{c} R_{u}}\left(T_{f}-T_{s}\right) \\
& -\left(\frac{C_{c}+C_{s}}{C_{c} C_{s} R_{c}}\right)\left(s T_{s}-T_{s, 0}\right)+\frac{1}{C_{s} R_{u}} s\left(T_{f}-T_{s}\right)
\end{aligned}
$$

where $T_{s, 0}$ is the initial surface temperature.

It is assumed here that $T_{f}$ is regulated as a steady output of the air-conditioning unit and thus $s T_{f}=0$, giving:

$$
\begin{aligned}
s^{2} T_{s}-s T_{s, 0}= & \frac{R_{e}}{C_{c} C_{s} R_{c}} I^{2}+\frac{1}{C_{c} C_{s} R_{c} R_{u}}\left(T_{f}-T_{s}\right) \\
& -\left(\frac{C_{c}+C_{s}}{C_{c} C_{s} R_{c}}+\frac{1}{C_{s} R_{u}}\right)\left(s T_{s}-T_{s, 0}\right)
\end{aligned}
$$

A filter will be designed and applied later to make the parametric model proper. If, in some cases, $T_{f}$ is fluctuating significantly, $s T_{f}$ should not be dropped and can be used as an extra varying input in the parametric model.

The parametric model in Equation (7) can be written in the form of Equation (6), where:

- the observation $z=s^{2} T_{s}-s T_{s, 0}$,

- the independent regressors $\phi=\left[I^{2}, T_{f}-T_{s}, s T_{s}-T_{s, 0}\right]^{T}$, - and the parameter vector $\theta=[\alpha \beta \gamma]^{T}$, with:

$$
\begin{aligned}
\alpha & =\frac{R_{e}}{C_{c} C_{s} R_{c}}, \quad \beta=\frac{1}{C_{c} C_{s} R_{c} R_{u}} \\
\text { and } \quad \gamma & =-\left(\frac{C_{c}+C_{s}}{C_{c} C_{s} R_{c}}+\frac{1}{C_{s} R_{u}}\right)
\end{aligned}
$$

By using parametric model Equation (7), only the three lumped parameters, $\alpha, \beta$ and $\gamma$, can be identified under the condition of persistent input excitation [13]. Prior knowledge of two of the physical parameters must be assumed so as to determine a set of unique solution for the original five physical parameters, $C_{c}, C_{s}, R_{e}, R_{c}$ and $R_{u}$ from $\alpha, \beta$ and $\gamma$.

Of the five physical parameters, the internal resistance $R_{e}$ may vary due to aging and needs to be identified. The thermal resistance $R_{c}$ is difficult to estimate, because it is a lumped parameter including both conduction and contact resistance. The convection resistance $R_{u}$ is influenced by the coolant flow conditions around the cell. Therefore, it is not easy to obtain prior knowledge of those three parameters. The heat capacities $C_{c}$ and $C_{s}$, which depend on the thermal properties and the mass of the jelly roll and the casing, are relatively constant over lifetime. In addition, the heat capacities will only affect the speed of transient response of the model without having any impact on the steady state temperatures. Consequently, the heat capacities $C_{c}$ and $C_{s}$ are selected to be the presumed parameters.

With $C_{c}$ and $C_{s}$ presumed and $\alpha, \beta$ and $\gamma$ identified, $R_{e}$, $R_{c}$ and $R_{u}$ can be obtained by:

$$
\begin{aligned}
& \beta\left(C_{c}+C_{s}\right) C_{s} R_{u}^{2}+\gamma C_{s} R_{u}+1=0 \\
& R_{c}=\frac{1}{\beta C_{s} C_{c} R_{u}} \\
& R_{e}=\alpha C_{c} C_{s} R_{c}
\end{aligned}
$$

The quadratic equation for $R_{u}$ in Equation (10) can lead to two solutions, but the right one can be decided by a rough estimation on the coolant flow conditions based on [14].

A second order filter should be applied to the observation and the regressors in Equation (7) to make them proper. The filter takes the form:

$$
\frac{1}{\Lambda(s)}=\frac{1}{\left(s+\lambda_{1}\right)\left(s+\lambda_{2}\right)}
$$

where $\lambda_{1}$ and $\lambda_{2}$ are designed based on the input and system dynamics.

The least squares algorithm in Equations $(3,5)$ can then be applied to implement model identification.

\section{ADAPTIVE OBSERVER DESIGN}

In this section, an adaptive observer which can perform online parameter and state estimation simultaneously is designed based on the recursive least squares model identification scheme and a model observer.

It is a common practice to design a closed loop observer, such as a Luenberger observer or a Kalman filter, to estimate the unmeasured states of a system based on measured signals and a model. The closed loop observer for a linear system:

$$
\dot{x}=A x+B u
$$

takes the form [15]:

$$
\begin{aligned}
& \dot{\hat{x}}=A \hat{x}+B u+L(y-\hat{y}) \\
& \hat{y}=C \hat{x}+D u
\end{aligned}
$$

where $x$ and $y$ are the actual system states and output, $\hat{x}$ and $\hat{y}$ are estimated states and output, $L$ is the observer gain, and $A$, $B, C$ and $D$ are model parameters. The difference between the measured and the estimated output is used as a feedback to correct the estimated states. The closed loop observer has certain advantages over the open loop observer (observer without output feedback). It can guarantee fast convergence of the estimated states to those of the real plant under uncertain initial conditions, e.g. a Luenberger observer [15], or optimize the estimation by balancing the effect of process and measurement noises, e.g. a Kalman filter [16]. 


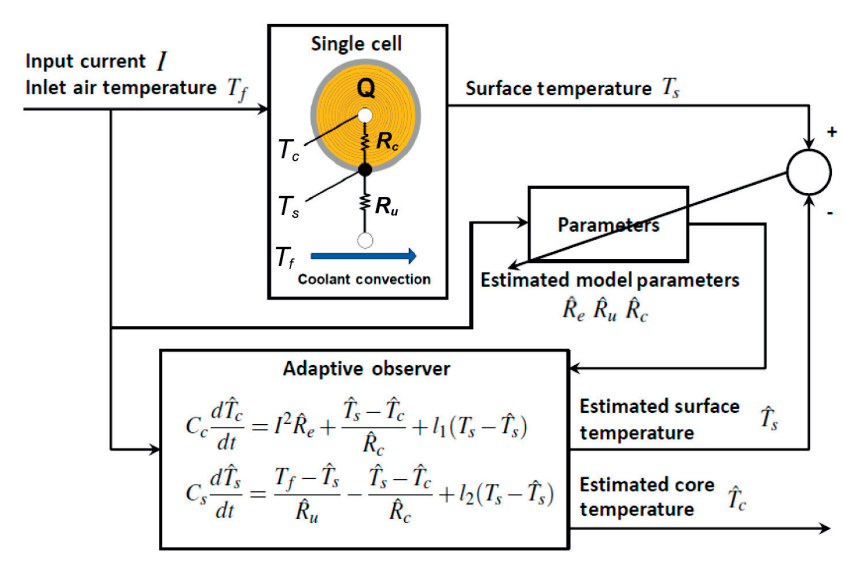

Figure 2

Online identification scheme and adaptive observer structure.

The cylindrical battery thermal model described by Equation (1) can be written in state space form as:

$$
\begin{aligned}
x & =\left[\begin{array}{ll}
T_{c} & T_{s}
\end{array}\right]^{T}, \quad y=T_{s}, \quad u=\left[\begin{array}{ll}
I^{2} & T_{f}
\end{array}\right]^{T} \\
A & =\left[\begin{array}{cc}
-\frac{1}{R_{c} C_{c}} & \frac{1}{R_{c} C_{c}} \\
\frac{1}{R_{c} C_{s}} & -\frac{1}{C_{s}}\left(\frac{1}{R_{c}}+\frac{1}{R_{u}}\right)
\end{array}\right] \\
B & =\left[\begin{array}{cc}
\frac{R_{e} R_{c}}{C_{c}} & 0 \\
0 & \frac{1}{R_{u} C_{s}}
\end{array}\right] \\
C & =\left[\begin{array}{ll}
0 & 1
\end{array}\right] \\
D & =0
\end{aligned}
$$

where the $C$ matrix clearly indicates that only the cell surface temperature can be measured. An adaptive observer is designed based on certainty equivalence principle [13], where the estimated parameters from online identification in Equation (5) are adopted for the observer. The structure of the whole online identification scheme and adaptive observer is shown in Figure 2.

As shown in Figure 2, the input current $I$, coolant temperature $T_{f}$ and measured surface cell temperature $T_{s}$ are fed into the parameter identifier to estimate model parameters $R_{u}, R_{e}$ and $R_{c}$. The adaptive observer, on one hand, adopts the estimated parameters for temperature estimation. On the other hand, it takes the errors between the measured and the estimated $T_{s}$ as a feedback to correct its core and surface temperature estimation. Estimations of both parameters and temperatures are updated at each time step.

\section{SIMULATION FOR PARAMETERIZATION AND ADAPTIVE OBSERVER FOR A CYLINDRICAL BATTERY THERMAL MODEL}

Simulation is used to verify the parameterization scheme and adaptive observer. A cylindrical battery thermal model in Equation (1) with parameters of an A123 32157

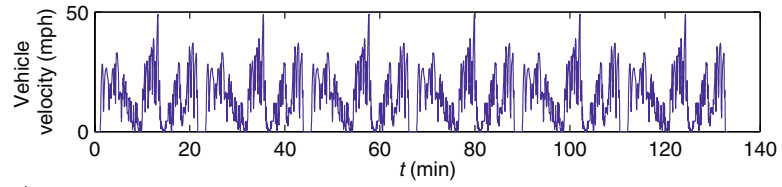

a)
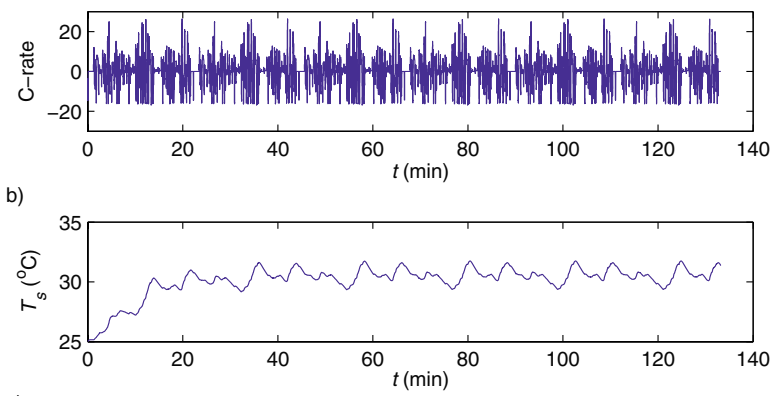

Figure 3

Simulated drive cycle and surface temperature output for verification. a) Vehicle velocity profile, b) corresponding battery current, c) simulated battery surface temperature.

$\mathrm{LiFePO}_{4} /$ graphite battery is used to generate data for methodology verification. These parameters are either taken from [17] and [10], by scaling the values to account for different cell geometries, or calculated based on [18]. The values of the model parameters are listed in Table 1.

TABLE 1

Nominal model parameters

\begin{tabular}{ccccc}
\hline$C_{c}\left(\mathrm{JK}^{-1}\right)$ & $C_{s}\left(\mathrm{JK}^{-1}\right)$ & $R_{e}(\mathrm{~m} \Omega)$ & $R_{c}\left(\mathrm{KW}^{-1}\right)$ & $R_{u}\left(\mathrm{KW}^{-1}\right)$ \\
\hline 268 & 18.8 & 3.5 & 1.266 & 0.79 \\
\hline
\end{tabular}

The coolant considered here is air, with $R_{u}=0.79 \mathrm{KW}^{-1}$ corresponding to an air flow rate of $9.5 \times 10^{-3} \mathrm{~m}^{3} / \mathrm{s}^{-1}$. The air flow temperature is fixed at $25^{\circ} \mathrm{C}$.

The Urban Assault Cycle (UAC) [19] is used to generate the current excitation. This drive cycle characterizes the typical high power excursion needed for military application. The vehicle velocity profile of UAC is plotted in Figure 3. The current load for the battery system is calculated for a 13.4 ton armored military vehicle in [19] and also plotted in Figure 3. As one can see that the UAC involves up to $20 \mathrm{C}$ battery discharging and $12 \mathrm{C}$ charging, including the current during regenerative braking. The UAC is repeated to generate a longer data set which is used as the model input to calculate the surface temperature $T_{s}$. The simulated core temperature is recorded for verification. The urban assault cycle current profile $I$ and the simulated $T_{s}$ are shown in Figure 3. The three parameters to be identified, $R_{u}, R_{c}$ and $R_{e}$, are initialized to be:

$$
R_{e}^{0}=10 \mathrm{~m} \Omega \quad R_{c}^{0}=2 \mathrm{KW}^{-1} \quad R_{u}^{0}=1.5 \mathrm{KW}^{-1}
$$

which are different from the nominal values in Table 1. 


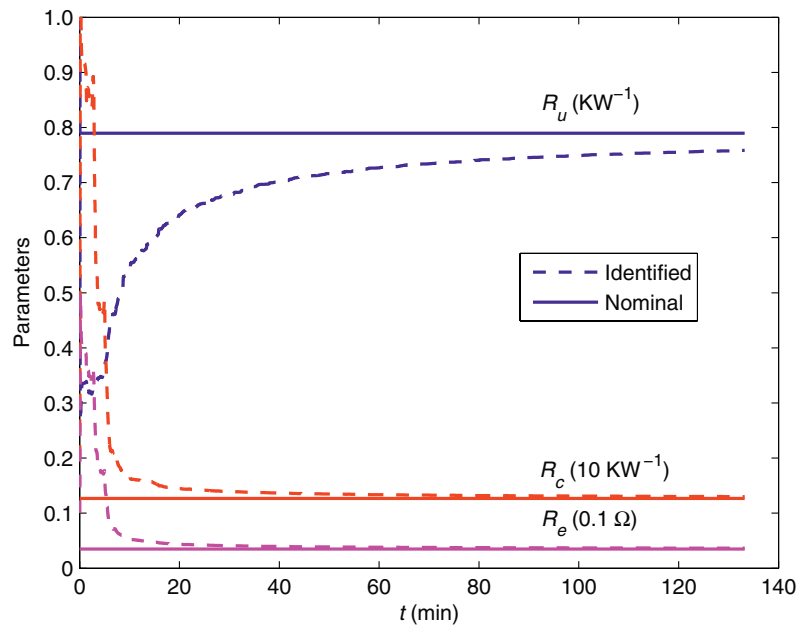

Figure 4

Online parameter identification results.

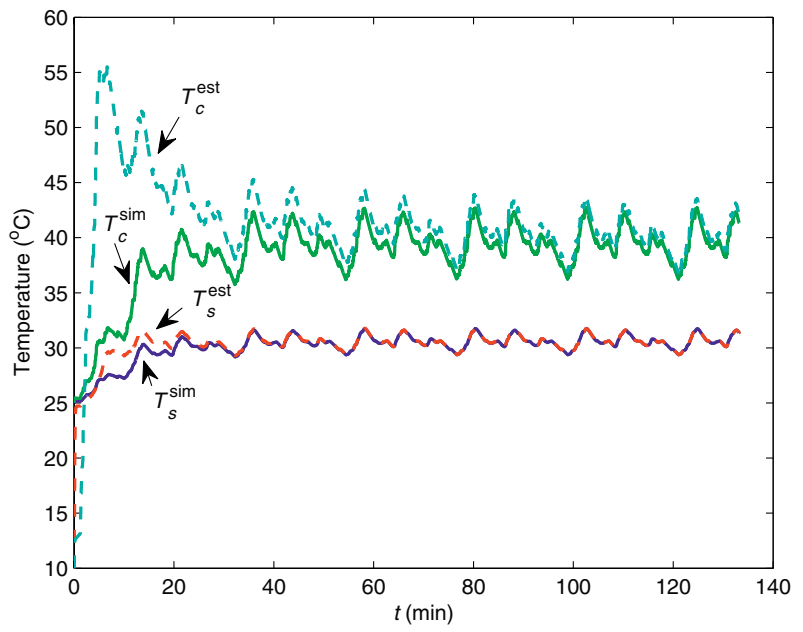

Figure 5

Adaptive observer response.
Under the drive cycle, the regressors $\phi$ in Equation (7) need to satisfy the persistent excitation condition in order for the parameterization algorithm to work [13]. The persistent excitation condition is satisfied if two positive numbers, $\alpha_{0}$ and $\alpha_{1}$, can be found such that [13]:

$$
\alpha_{1} I_{M} \geq U(t)=\frac{1}{T_{0}} \int_{t}^{t+T_{0}} \phi(\tau) \phi^{T}(\tau) d \tau \geq \alpha_{0} I_{M} \quad \forall t \geq 0
$$

where $T_{0}$ is a certain time interval and $I_{M}$ is the identity matrix. Here, $T_{0}$ is chosen as the period of one UAC cycle, which is 1332 seconds, to calculate the $U(t)$ matrix. Once the battery reaches the thermal quasi steady state, after about 30 minutes, the surface temperature varies periodically with period $T_{0}$. Consequently, the calculated $U(t)$ is constant over time. The $U$ matrix is a symmetric matrix, whose maximum and minimum eigenvalues are 0.3 and 0.005 respectively. These two numbers can be used as the $\alpha_{0}$ and $\alpha_{1}$ in Equation (16) to satisfy the persistent excitation condition.

The online identification results are plotted in Figure 4. It can be seen that all the three parameters converge to the nominal values in Table 1, despite starting at some random initial values. Both the identified $R_{e}$ and $R_{c}$ converge within 10 minutes whereas $R_{u}$ takes longer. The response of the adaptive observer is plotted in Figure 5. In this figure, the temperatures $T_{c}$ and $T_{s}$ simulated by the model (emulating the real battery) are presented and the estimated $T_{c}$ and $T_{s}$ are plotted to evaluate the performance of the adaptive observer. The simulated core temperature $T_{c}$ and surface temperature $T_{s}$ are initialized to be $25^{\circ} \mathrm{C}$ and the adaptive observer starts from $10^{\circ} \mathrm{C}$ for both temperatures. It is noted that the estimated surface temperature converges to the real values within 20 minutes, because the $T_{s}$ is directly measured and fed back into the observer to force the observer to match the measurement. The estimation of the core temperature, $T_{c}$, instead, converges much slower (in about 60 minutes). This slower adaption occurs because $T_{c}$ is not directly measured and thus the estimation of $T_{c}$ will heavily depend on the precision of the observer parameters. It can be seen in Figure 4 that the parameters estimated by the identifier fluctuate for a while before finally converging to the correct values. The convergence of $T_{c}$ estimation happens after the parameter identification converges.

Experimental validation (with core temperature measurement) of the parameter identification algorithm has been performed on an $A 12326650$ battery and documented on a separate article [20].

\section{SCALABLE BATTERY CLUSTER THERMAL MODEL AND SENSOR DEPLOYMENT ANALYSIS}

In vehicle application, batteries are usually packed in modules to satisfy the energy and power demand. This section is devoted to constructing a thermal model for a battery cluster based on the previously discussed single cell model. The cluster model can then be used to design an thermal observer for the cluster. The parameters identified by the online identifier discussed above can be updated in real time to the cluster model for adaptation. To optimize temperature estimation, a closed loop observer with surface temperature feedback is desirable, which will require observability. The observability analysis will then be conducted to the cluster thermal model to guide the sensor deployment. 


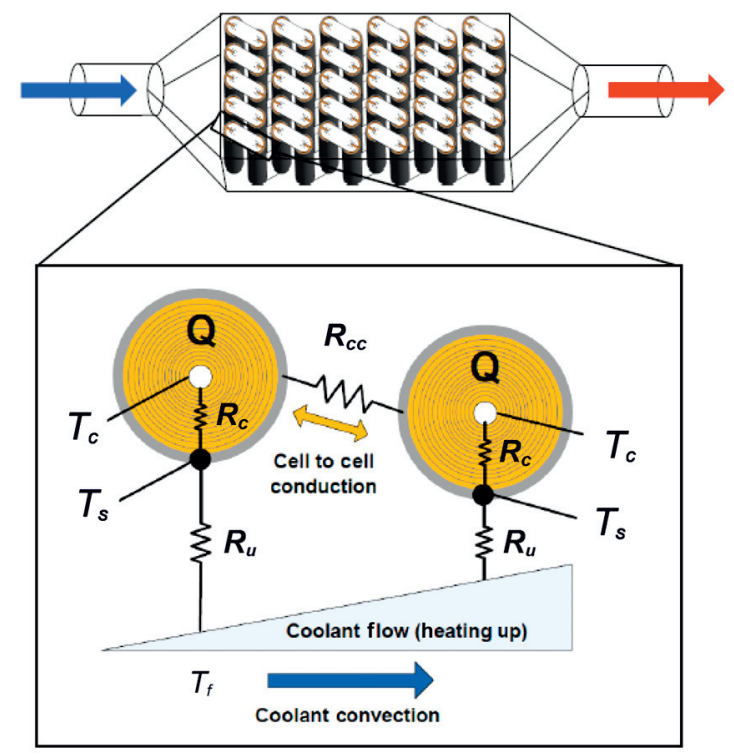

Figure 6

A possible battery pack configuration, with 5 strings of 12 cells along the coolant path.
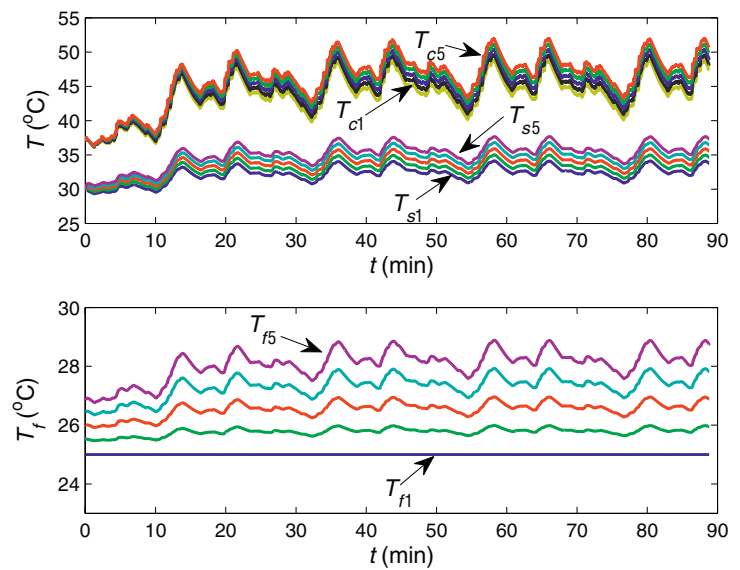

Figure 7

Simulated battery pack temperature profile subject to UAC cycle (for $T_{c}, T_{s}$ and $T_{f}$, from cooler to hotter: Cell1, Cell2, Cell3, Cell4 and Cell5).

\subsection{Scalable Battery Cluster Thermal Model}

The single cell cylindrical battery thermal model in Equation (1) can be scaled up to a battery cluster model by considering cell to cell heat conduction [21] and heat balance of the flowing coolant $[6,11]$, as shown in Figure 6.

As shown in Figure 6, the cluster can be simplified by considering cells that are connected in series with tabs and are geometrically arranged in a row configuration along the coolant flow path. The coolant flows through the space between cells from the inlet to the outlet and picks up the heat dissipated from the cell surface through convection.

The temperature evolution of the $k$ th cell in a cluster can be modeled as:

$$
\begin{aligned}
C_{c} \frac{d T_{c, k}}{d t} & =I^{2} R_{e}+\frac{T_{s, k}-T_{c, k}}{R_{c}} \\
C_{s} \frac{d T_{s, k}}{d t} & =\frac{T_{f, k}-T_{s, k}}{R_{u}}-\frac{T_{s, k}-T_{c, k}}{R_{c}}+\frac{T_{s, k-1}+T_{s, k+1}-2 T_{s, k}}{R_{c c}} \\
T_{f, k} & =T_{f, k-1}+\frac{T_{s, k-1}-T_{f, k-1}}{R_{u} C_{f}}
\end{aligned}
$$

where $k$ is the index of the cell along the coolant flow direction.

In Equation (17), the heat conduction between cells is modeled as heat flow over a conduction resistance $R_{c c}$, driven by the temperature difference between the adjacent cell surfaces. It is noted here that $R_{c c}$ is a lumped parameter, which may include heat conduction through the tab and other possible connections between cells depending on the cluster structure. The coolant flow temperature of the $k$ th cell, $T_{f, k}$, is determined by heat balance of the flow around the previous cell, which is calculated by dividing the heat removed $\left(T_{s, k-1}-T_{f, k-1}\right) / R_{u}$ from the $(k-1)$ th cell by the coolant flow capacity $C_{f}$. It is assumed that all the cells have the same parameters and the current is also the same for all the cells since the cluster is in series connection.

The temperature profile for a cluster with 5 cells subject to Urban Assault Cycle (UAC) is shown in Figure 7. Cell1 is close to the coolant inlet while Cell5 is close to the outlet. The inlet air temperature for this simulation is set at $25^{\circ} \mathrm{C}$ and the flow rate is $9.5 \times 10^{-3} \mathrm{~m}^{3} \mathrm{~s}^{-1}$, corresponding to a flow velocity of $1.515 \mathrm{~m} \cdot \mathrm{s}^{-1}$.

In Figure 7, the coolant air temperature $T_{f}$ for Cell1 stays constant at $25^{\circ} \mathrm{C}$ since the inlet air temperature is controlled. As the coolant air flows from Cell1 to Cell5, its temperature $T_{f}$ increases as it picks up the heat from the cells. Consequently, the surface and the core temperatures of the cells will also increase down the string towards the coolant outlet due to the coolant temperature rise.

Here, it is assumed that every single cell in the string has the same $R_{u}$. As can be seen in Figure 7, the hottest cell will be the last one because the difference in cooling among cells is only affected by the coolant temperature and thus the heat rejection capacity for each cell is the same. For some pack geometries, it might be possible that different cells are subject to different flow conditions, e.g. the cells at the two ends of the string may have higher heat rejection capacity due to the larger space around them. Therefore, the cells in the middle of the string may have the highest 
temperatures. For those cases, different $R_{u}$ numbers can be applied to different cells to capture these variations.

\subsection{Model based Prediction of the Cluster Temperatures}

In a commercial battery module for automotive application, there are usually hundreds or even thousands of cells in total, and it is not possible to measure the surface temperature for every single cell. One common practice is to test the pack before installation and identify those cells with the highest temperature under experiment conditions and place thermocouples on those cells to monitor the critical temperatures as a reference for cooling control and power management. One potential issue with such method is that it cannot provide the temperatures of every single cell and hence capture the thermal non-uniformity across the pack during transients. Consequently, model based temperature monitoring might be highly desirable sin ce it can estimate the core temperature $T_{c}$ and the surface temperature $T_{s}$ of every cell in the pack.

The cluster thermal model developed in this paper can be used for cluster thermal monitoring. A model based state estimator can be categorized as either an open loop observer or a closed loop observer. An open loop observer estimates the states with the model solely based on the inputs. For example, considering a battery string with 2 cells, an open loop observer takes the form in Equation (12), with:

$$
\begin{aligned}
& x=\left[\begin{array}{llll}
T_{c, 1} & T_{s, 1} & T_{c, 2} & T_{s, 2}
\end{array}\right]^{T}, \quad u=\left[\begin{array}{ll}
I^{2} & T_{f}
\end{array}\right]^{T} \\
& B=\left[\begin{array}{cc}
\frac{R_{e}}{C_{c}} & 0 \\
0 & \frac{1}{R_{u} C_{s}} \\
\frac{R_{e}}{C_{c}} & 0 \\
0 & \frac{R_{u} C_{f}-1}{R_{u}^{2} C s C f}
\end{array}\right]
\end{aligned}
$$

and the $A$ matrix specified in Equation (19).

The open loop observer will give accurate state estimation if the initial conditions of all the temperature states are known, which naturally occurs when all the cells in the pack relax to the coolant temperature.

When the initial conditions are not known, the estimated temperatures will still converge to the real temperatures gradually since the thermal system is stable but the convergence will be slow due to the slow thermal dynamics of the battery. Unknown initial conditions (temperatures) will often occur in a battery pack. Since the temperature sensors can only be installed on some cell surfaces, only the initial surface temperatures of those cells can be obtained precisely at startup while the initial core temperatures remain unknown. If the vehicle is started from steady states, e.g. after overnight rest, the unmeasured initial core temperatures of the cells can be assumed to be the same as the measured initial surface temperatures. But such an assumption may not be valid for short shutdown. Figure 8 shows the simulated temperature evolution during shutdown of a battery pack with 5 cells in series. The temperature profile of the precedent operation cycle is shown in Figure 7. The current is cut off at the beginning of the simulation in Figure 8 as the shutdown is initiated, and the cooling system is kept on during the shutdown process.

It can be observed in Figure 8 that it takes the battery pack more than 40 minutes for all the cells to cool down to the ambient temperature when the surface temperatures $T_{s}$ and the core temperatures $T_{c}$ are equal. In real application,

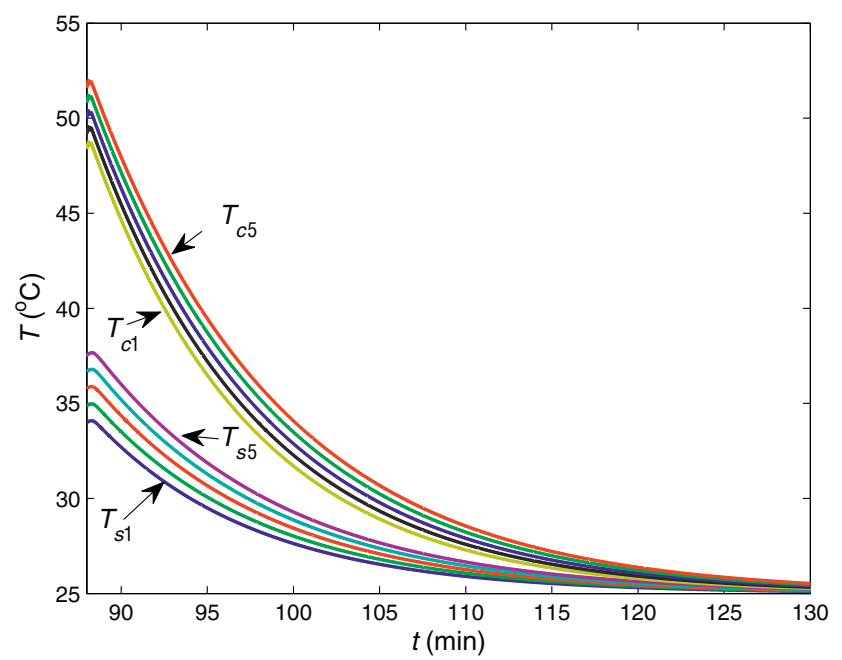

Figure 8

Simulated battery pack temperature profile during shutdown (for $T_{c}, T_{s}$ and $T_{f}$, from bottom to top: Cell1, Cell2, Cell3, Cell4 and Cell5).

$$
A=\left[\begin{array}{cccc}
-\frac{1}{R_{c} C_{c}} & \frac{1}{R_{c} C_{c}} & 0 & 0 \\
\frac{1}{R_{c} C_{s}} & -\left(\frac{1}{R_{c} C_{s}}+\frac{1}{R_{u} C_{s}}+\frac{1}{R_{c c} C_{s}}\right) & 0 & \frac{1}{R_{c c} C_{s}} \\
0 & 0 & -\frac{1}{R_{c} C_{c}} & \frac{1}{R_{c} C_{c}} \\
0 & \left(\frac{1}{R_{u}{ }^{2} C_{f} C_{s}}+\frac{1}{R_{c c} C_{s}}\right) & \frac{1}{R_{c} C_{s}} & -\left(\frac{1}{R_{u} C_{s}}+\frac{1}{R_{c} C_{s}}+\frac{1}{R_{c c} C_{s}}\right)
\end{array}\right]
$$


it may not be feasible to keep the cooling system on for 40 minutes after key-off. Consequently, the actual time for the pack to cool down will be longer since the convection will be weakened in absence of forced coolant flow. If the driver tries to turn the vehicle back on before the pack gets to thermal equilibrium, the initial reading of the surface temperature at startup will not be a good approximation for the initial core temperatures. The shorter the shutdown is, the larger the errors of such approximation will be. For example, if the next startup occurs at about 10 minutes after the previous shutdown, according to Figure 8, the difference between the surface and the core temperatures will be roughly $7^{\circ} \mathrm{C}$.

A simulation has been conducted to investigate how fast the open loop estimation of the temperatures will converge under such errors in initial conditions. In simulation, the real initial surface and core temperatures of all the cells are set to be $30^{\circ} \mathrm{C}$ and $37^{\circ} \mathrm{C}$ respectively. For the open loop observer, the initial core temperatures are assumed to be the same as the measured surface temperatures, which are $30^{\circ} \mathrm{C}$. The results are shown in Figure 9. For clarity, only the temperatures of Cell1 and Cell5 are plotted.

It can be observed in Figure 9 that the settling time for open loop estimation of the surface and core temperatures for both Cell1 and Cell5 is more than 30 minutes. Such a big delay is due to the slow thermal dynamics of the batteries and may lead to ineffective battery management during the startup period. It is noted that in onboard BMS, not every cell surface temperature is measured. As a result, in addition to the unknown core temperatures considered here, the surface temperatures of those unmeasured cells will also be
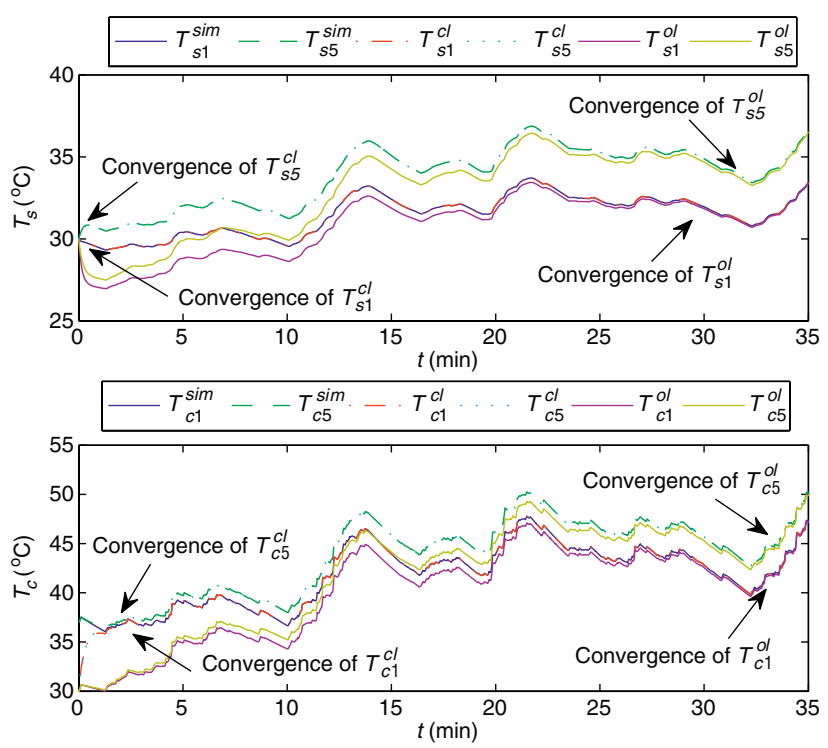

Figure 9

Convergence of open loop and closed loop observer. unknown at startup. Such uncertainty may further increase the delay of convergence.

In order to minimize delay in estimation due to unknown initial temperatures, a closed loop observer can be designed to achieve fast estimator convergence. For a closed loop observer, some of the states (cell surface temperatures) are measured and the errors between the measurement and the estimation are fed back to the model-based observer to correct the estimation [15]. Taking a cell string with 2 cells as an example, the closed loop observer takes the form in Equation (13), where the $A$ matrix is specified in Equation (19), and $x, u$ and $B$ in Equation (18). If a thermocouple is used to measure the surface temperature of the second cell, we will have:

$$
C=\left[\begin{array}{llll}
0 & 0 & 0 & 1
\end{array}\right], \quad D=0
$$

When the model is completely observable, by tuning the observer gains, the dynamics of the closed loop observer can be designed to be fast and the estimated temperatures will converge to the real plant temperatures much more quickly than the open loop estimation when starting from unknown initial temperatures.

Simulation for a closed loop temperature observer is shown in Figure 9 to compare with the performance of the open loop observer. It can be seen that the closed loop estimation converges to the real temperatures much faster than the open loop estimation. Both temperatures estimated by the closed loop observer converge to the real temperatures within 5 minutes, as compared to the 30 minutes taken by the open loop observer. It is noted that simulation in Figure 9 assumes known parameters for all the cells, which are identified by the previous single cell identifier. That is why the estimated temperatures can converge fast to the correct values.

Under the current strategy, thermal parameters are identified for cells with thermocouples in the battery pack. The identified parameters are then used for pack temperature estimation as batteries without thermocouples are assumed to have the same parameter values. It is shown next that the pack closed loop observer will have smaller estimation errors than the open loop observer, even if the assumption that all cells have identical thermal characteristics is false. Simulation has been conducted with a battery string with 5 cells in series to evaluate the effect of nonidentical cell thermal properties on temperature estimation. The surface temperatures of Cell1 and Cell5 are accessible by the observer and their internal resistances are set to be $3.5 \mathrm{~m} \Omega$. The other cells, Cell2 to Cell4, whose surface temperatures are not accessible, are set with internal resistance of $4.3 \mathrm{~m} \Omega$. The observer will have the correct internal resistance value, $3.5 \mathrm{~m} \Omega$, for the 1 st and 5 th cell since their surface temperatures are available for identification, and it will assume the same value for Cell2 to Cell4, whose internal resistances are actually $4.3 \mathrm{~m} \Omega$. In Figure 10, temperature estimations of Cell1 and Cell4 by the open loop observer 

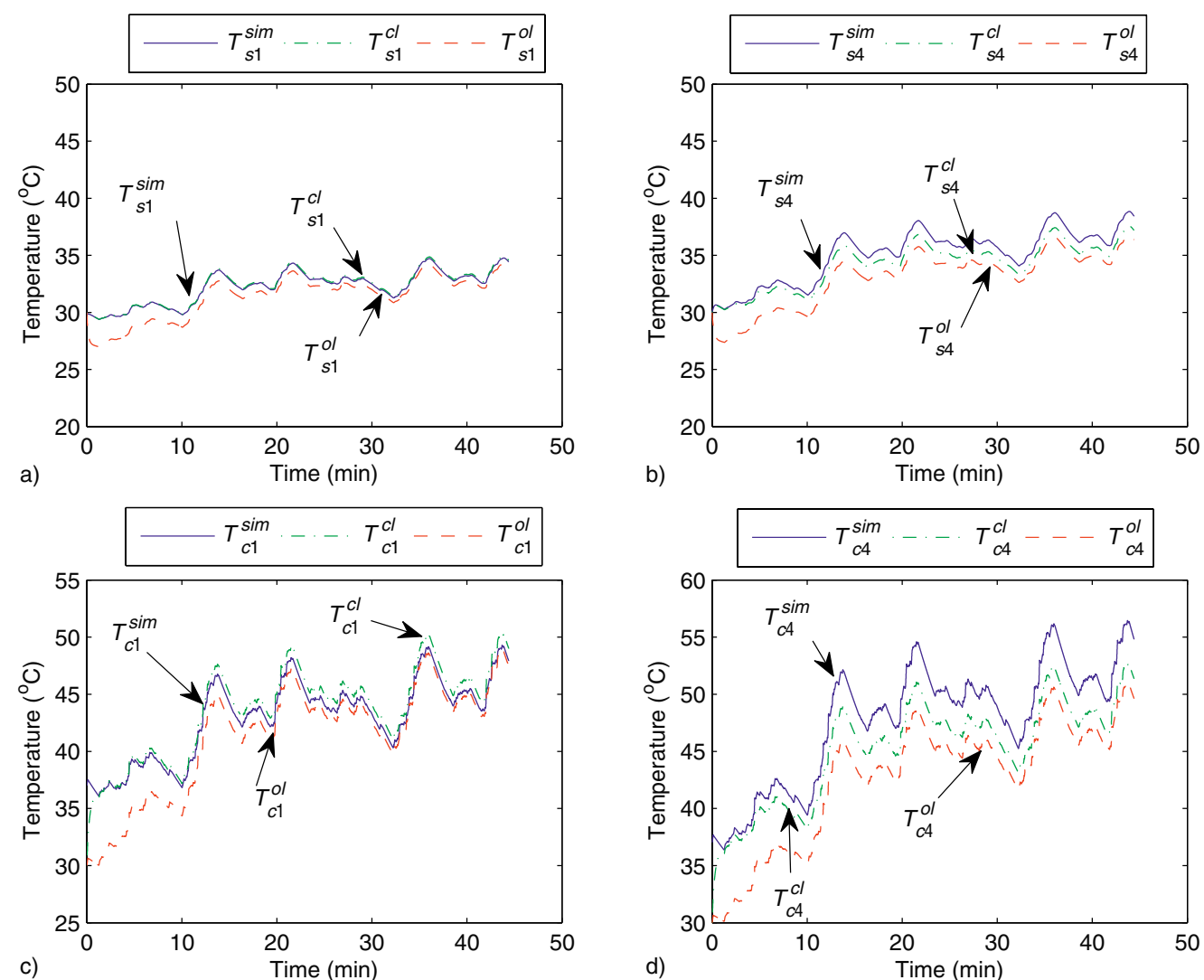

Figure 10

Convergence of the temperature estimation by open loop and closed loop observer. a) $T_{s 1}$, b) $T_{s 4}$, c) $T_{c 1}$, d) $T_{c 4}$.

are plotted and compared with the simulated real temperatures. Errors can be observed in the open loop estimation $\left(T_{s i}^{o l}, T_{c i}^{o l}\right)$, especially for the fourth cell, whose internal resistance is assumed with an erroneous value in the observer. Similar errors exist in the temperature estimations of Cell2 and Cell3, which are not plotted. For the 1st cell, although the model parameters in the observer are correct, the temperature estimation is still erroneous as the errors propagate from the biased estimation of other cells through cell to cell conduction. The closed loop observer can greatly reduce the estimation error under such circumstance, as plotted in Figure 10, especially for Cell4. The two and infinity norms of the temperature estimation errors for all 5 cells by both open and closed loop observers are shown in Figure 11 indicating that the overall errors in temperature estimation are also smaller for the closed loop observer. It is noted that the closed loop observer cannot eliminate the estimation errors due to erroneous model parameters of unidentified cells. The ultimate solution will be to identify the parameters of multiple cells based on surface temperature measurement of one or several batteries in a cell string.
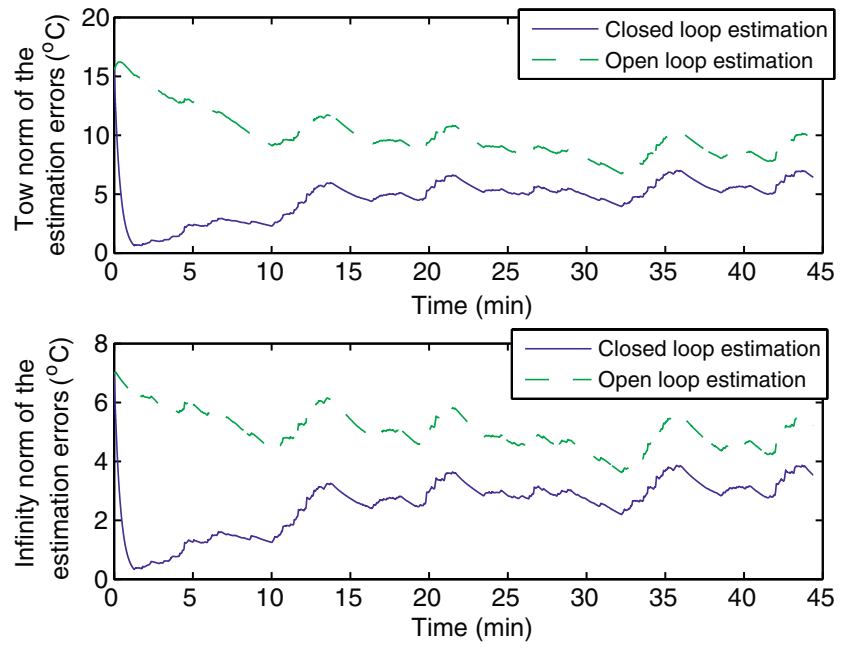

Figure 11

Norms of the estimation errors for open loop and closed loop observer. 


\subsection{Investigation on Sensor Deployment based on Cluster Model Observability Analysis}

An effective closed loop observer is based on the observability of the battery pack model. In this section, the observability conditions are analyzed to guide the sensor placement in specific cells in the battery pack so as to enable an effective error correction.

The observability of a model can be examined by its observability matrix:

$$
Q=\left[\begin{array}{c}
C \\
C A \\
\cdots \\
C A^{n-1}
\end{array}\right]
$$

where $A$ is the system matrix, $C$ is the output matrix in Equation (12) and $n$ is the order of the system. The model will be completely observable if and only if the rank of $Q$ is equal to $n$.

First, a battery string with 2 cells, whose $A$ matrix is specified in Equation (19), is investigated for simplicity. In Equation (19), the $1 / R_{c c} C_{s}$ terms in the 2 nd and the 4 th rows of the $A$ matrix reflect the thermal interaction between the 2 cells through cell to cell conduction. The $1 /\left(R_{u}{ }^{2} C_{f} C_{s}\right)$ term in the 4th row represents the impact of the first cell on the second one through coolant flow convection. The absence of this term in the 2nd row indicates that such impact is unidirectional and the second cell cannot influence the first cell via coolant convection.

The $C$ matrix will be determined by the location of the sensor. If the surface temperature of Cell1 is measured, then $C_{1}=\left[\begin{array}{llll}0 & 1 & 0 & 0\end{array}\right]$, and if the surface temperature of Cell2 is measured, $C_{2}=\left[\begin{array}{llll}0 & 0 & 0 & 1\end{array}\right]$.

If all the elements in $A$ are assigned with the values assumed in this paper and applied to Equation (21) to calculate $Q$, it can be found that the rank of $Q$ will be 4 when either $C_{1}$ or $C_{2}$ is applied. This means that for a cell string with 2 cells, either measuring the first or the second cell will give full observability.

For a cell string with 3 cells in series, the $A$ matrix can be established as Equation (22). Similar to the $A$ matrix for the 2 cell string in Equation (19), the $1 /\left(R_{c c} C_{s}\right)$ terms in the 2nd, 4th and 6th rows reflect the interaction between the adjacent cells via cell to cell heat conduction, and the $1 /\left(R_{u}{ }^{2} C_{f} C_{s}\right)$ term in the 4 th row accounts for the impact of the first cell on the second cell by coolant flow convection. More details about the cell interconnection via coolant convection can be revealed by exploring the 6th row of the $A$ matrix. In the 6th row, the $1 /\left(R_{u}{ }^{2} C_{f} C_{s}\right)$ term in the 4th column represents the impact of the second cell on the third cell through coolant convection and the $1 /\left(R_{u}{ }^{2} c_{f} c_{s}\right)-1 /\left(R_{u}{ }^{3} c_{f}{ }^{2} c_{s}\right)$ term in the 2 nd column describes such impact of the first cell on the third cell. It can be seen that all the previous cells in the string will affect the subsequent cells through coolant flow convection and the further apart the two cells are, the weaker such effect will be. Such feature of the coolant convection is different from that of the cell to cell conduction, which only exists between adjacent cells and the strength is always the same.

For cell strings with any number of cells, after establishing the $A$ matrix similar to Equation (19) and Equation (22), observability analysis can be conducted to find the minimum number of sensors that gives full observability. The results are summarized in Table 2 .

TABLE 2

\begin{tabular}{cc} 
Minimum number of sensors for a battery strin \\
\cline { 2 - 2 } No. of cells & Min. no. of sensors \\
\hline $1,2,3$ & 1 \\
$4,5,6$ & 2 \\
$7,8,9$ & 3 \\
$10,11,12$ & 4 \\
\hline
\end{tabular}

It is noted that for cell strings with more than 5 cells, the sensor location will also have an effect on the observability. For example, for a string with 5 cells, although the minimum number of sensors for full observability is 2 , different sensor locations may lead to different results on observability, as shown in Figure 12. It can be seen that if the 2 sensors are placed at the first 2 cells, the rank of the $Q$ matrix will be less than 10 , hence the full observability cannot be satisfied.

$$
A_{-3 \text { cell }}=\left[\begin{array}{cccccc}
-\frac{1}{R_{c} c_{c}} & \frac{1}{R_{c} c_{c}} & 0 & 0 & 0 & 0 \\
\frac{1}{R_{c} c_{s}} & -\left(\frac{1}{R_{c} c_{s}}+\frac{1}{R_{u} c_{s}}+\frac{1}{R_{c c} c_{s}}\right) & 0 & \frac{1}{R_{c c} c_{s}} & 0 & 0 \\
0 & 0 & -\frac{1}{R_{c} c_{c}} & \frac{1}{R_{c} c_{c}} & 0 & 0 \\
0 & \frac{1}{R_{u}^{2} c_{f} c_{s}}+\frac{1}{R_{c c} c_{s}} & \frac{1}{R_{c} c_{s}} & -\left(\frac{1}{R_{u} c_{s}}+\frac{1}{R_{c} c_{s}}+\frac{2}{R_{c c} c_{s}}\right) & 0 & \frac{1}{R_{c c} c_{s}} \\
0 & 0 & 0 & 0 & \frac{1}{R_{c} c_{c}} & \frac{1}{R_{c} c_{c}} \\
0 & \frac{1}{R_{u}^{2} c_{f} c_{s}}\left(1-\frac{1}{R_{u} c_{f} c_{s}}\right) & 0 & \frac{1}{R_{c c} c_{s}} & \frac{1}{R_{c} c_{s}} & -\left(\frac{1}{R_{c} c_{s}}+\frac{1}{R_{u} c_{s}}+\frac{1}{R_{c c} c_{s}}\right)
\end{array}\right]
$$




\section{Sensor location}

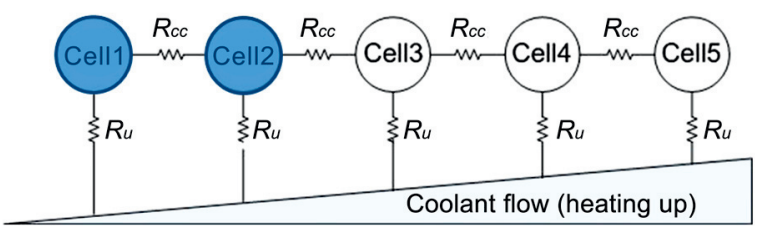

$\operatorname{Rank}(Q)=9$ (not fully observable)

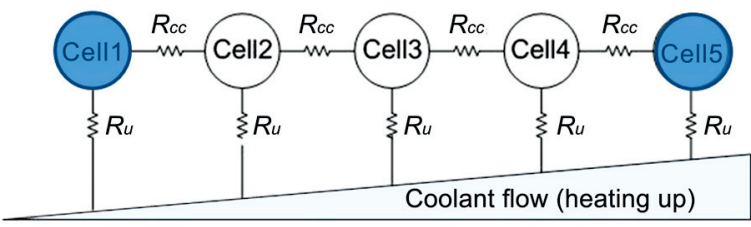

$\operatorname{Rank}(Q)=10$ (fully observable)
Sensor location

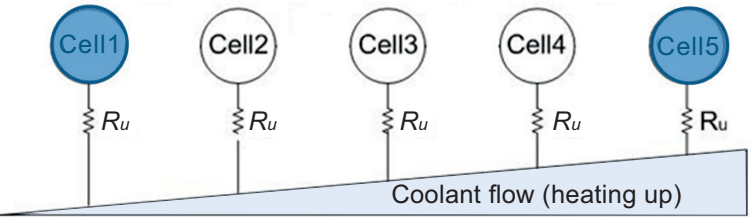

No cell to cell conduction: $\operatorname{Rank}(Q)=9$ (not fully observable)

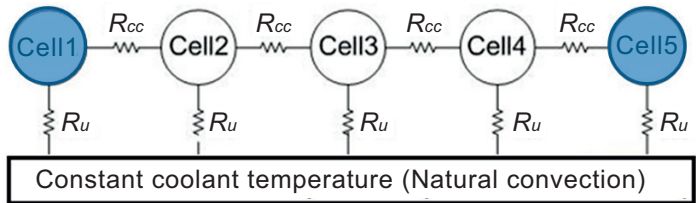

Natural conduction: $\operatorname{Rank}(Q)=10$ ( fully observable)

Figure 13

Observability of the same sensor locations under different conditions.

Sensor location determines full observality.

Under these circumstances, the observability conditions will be different. Take a cell string with 5 cells as an example. As shown in Figure 13, when the coolant circulation is disabled and the cells are cooled by natural convection, placing the sensors at the first and the last cell can still satisfy observability condition. But when the cell to cell conduction is missing, the same sensor locations cannot give full observability.

Such discussion can be generalized to strings with more cells. A string with 12 cells is analyzed and the results are summarized in Table 3 . The minimum number of sensors that gives full observability is 4 . As shown in Table 3, among all the 495 combinations of 4 sensor locations in a cell string of 12 , if there are both circulated coolant convection and cell to cell conduction, referred to as full interconnection in Table 3, 106 combinations will give full observability. Under natural convection, where the coolant is not flowing between cells, only 52 combinations can satisfy full observability condition. When the cell to cell conduction is missing, only 1 combination yields full

TABLE 3

Number of sensor position combinations giving full observability for a string with 12 cells and 4 sensors

\begin{tabular}{cc}
\hline Conditions & $\begin{array}{c}\text { No. of combinations } \\
\text { giving full observability }\end{array}$ \\
\hline Full interconnection & $106 / 495$ \\
Natural convection & $52 / 495$ \\
No cell to cell conduction & 1 \\
\hline
\end{tabular}


observability. That combination would be evenly distributing the sensors at the 3th, 6th, 9th and 12th cells, which quite agrees with intuition.

Of the two modeled thermal interconnections between cells, namely the cell to cell heat conduction and the heat convection through the coolant flow, the former tends to have larger impact on the observability of the pack model. This may be related to the fact that the cell to cell heat conduction is a two-way interaction, whereas the heat convection through the coolant flow is single directional.

Consequently, greater cell to cell heat conduction is favored by the observability of the pack model. It is noted that great cell to cell heat conduction can also reduce the temperature gradient between cells in the pack and thus help contain the imbalance between cells induced by temperature non-uniformity. However, on the negative side, in case of a single cell thermal failure, e.g. local overheating, the great cell to cell heat conduction will facilitate the spread of such failure to other cells in the pack, which is not desirable from a safety perspective.

\section{CONCLUSION}

In this paper, an online parameterization methodology for a lumped thermal model of a cylindrical lithium ion battery cell has been proposed, designed and verified by simulation. By using the online parameterization algorithm, the lumped parameters of the thermal model, which cannot be easily measured or calculated otherwise, can be automatically identified based on the current excitation of a real drive cycle and the resultant battery surface temperatures. The identified parameters and the measured cell surface temperature are adopted by an adaptive observer to estimate the unmeasured core temperature of the cell. The estimated core temperature is a more effective reference for the onboard thermal management and the vehicle power management system. The next step will be to validate the model and the methodology with experiments. Over the battery lifetime, such online identification scheme can be reset on a monthly or yearly basis to track varying parameters due to degradation. This can also be achieved by using forgetting factors, which has been explored in another publication [12].

The single cell model is then scaled up to a onedimensional cluster model after being augmented with cell to cell heat conduction and coolant flow thermal dynamics due to convection. The cluster model can be further scaled to multi-dimensional models with more complicated thermal connections between cells. Different cooling strategies and configurations for the pack can be accommodated by tuning the values of the parameters. The observability of the cluster model is investigated to enlighten pack sensor deployment. The system matrix of the cluster model has been explored and minimum numbers of required sensors have been determined for clusters with various lengths. The sensor locations will affect the observability of the cluster, and such impacts are different under various cluster constructions and cooling conditions.

At this point, the adaptation of the cluster thermal monitoring is achieved by propagating the parameters identified online from a single cell to the whole cluster. The underlying assumption is that all the cells are behaving and degrading at the same pace. To achieve full adaptation of the cluster, where degradation profile can be established for the cluster, the sensor deployment will be investigated based on the identifiability analysis of the cluster model.

\section{ACKNOWLEDGMENTS}

Thanks to the US Army Tank Automotive Research, Development and Engineering Center (TARDEC), Automotive Research Center (ARC), a US Army center of excellence in modeling and simulation of ground vehicles, and Ford Motor Company for funding this work.

\section{REFERENCES}

1 Nguyen J., Taylor C. (2004) Safety performance of a large format, phosphate based lithium-ion battery, 26th Annual International Telecommunications Energy Conference (INTELEC 2004), Chicago, Illinois, 19-23 Sept.

2 Mi C., Li B., Buck D., Ota N. (2007) Advanced electro-thermal modeling of lithium-ion battery system for hybrid electric vehicle applications, IEEE Vehicle Power and Propulsion Conference (VPPC 2007), Arlington, Texas 9-12 Sept., pp. 107-111.

3 Bernardi D., Pawlikowski E., Newman J. (1985) A general energy balance for battery systems, J. Electrochem. Soc. 132, 5-12.

4 Gu W.B., Wang C.Y. (2000) Thermal-electrochemical modeling of battery systems, J. Electrochem. Soc. 147, 2910-2922.

5 Al Hallaj S., Maleki H., Hong J.S., Selman J.R. (1999) Thermal modeling and design considerations of lithium-ion batteries, J. Power Sources 83, 1-8.

6 Mahamud R., Park C.W. (2011) Reciprocating airflow for li-ion battery thermal management to improve temperature uniformity, J. Power Sources 196, 5685-5696.

7 Maleki H., Shamsuri A.K. (2003) Thermal analysis and modeling of a notebook computer battery, J. Power Sources 115, 131-136.

8 Smith K., Wang C.Y. (2006) Power and thermal characterization of a lithium-ion battery pack for hybrid-electric vehicles, J. Power Sources 160, 662-673.

9 Wang C.Y., Srinivasan V. (2002) Computational battery dynamics (cbd) - electrochemical/thermal coupled modeling and multi-scale modeling, J. Power Sources 110, 364-376.

10 Forgez C., Do D.V., Friedrich G., Morcrette M., Delacourt C. (2010) Thermal modeling of a cylindrical lifepo4/graphite lithium-ion battery, J. Power Sources 195, 2961-2968. 
11 Park C.W., Jaura A.K. (2003) Dynamic thermal model of li-ion battery for predictive behavior in hybrid and fuel cell vehicles, SAE Technical Paper 2003-01-2286.

12 Lin X., Perez H.E., Siegel J.B., Stefanopoulou A.G., Li Y., Anderson R.D. (2012) Quadruple adaptive observer of li-ion core temperature in cylindrical cells and their health monitoring, American Control Conference (ACC 2012), Montreal, Canada, 27-29 June.

13 Ioannou P.A., Sun J. (1996) Robust Adaptive Control, Prentice Hall.

14 Zukauskas A. (1972) Heat transfer from tubes in crossflow, Adv. Heat Transfer 8, 93-160.

15 Williams II R.L., Lawrence D.A. (2007) Linear state-space control systems, Wiley.

16 Kalman R.E. (1960) A new approach to linear filtering and prediction problems, Trans. ASME J. Basic Eng. 82 (Series D), 35-45.

17 A123Systems (2006) Datasheet: High Power Lithium Ion ANR26650M1 A123Systems Inc. www.a123systems.com.
18 Incropera F.P., DeWitt D.P. (1985) Fundamentals of heat and mass transfer, John Wiley and Sons Inc., New York, NY.

19 Tae-Kyung L., Youngki K., Stefanopoulou A.G., Filipi Z. (2011) Hybrid electric vehicle supervisory control design reflecting estimated lithium-ion battery electrochemical dynamics, American Control Conference (ACC 2011), San Fransisco, California, 29 June-1 July, pp. 388-395.

20 Lin X., Perez H.E., Siegel J.B., Stefanopoulou A.G., Li Y., Anderson R.D., Ding Y., Castanier M.P. (2012) Online parameterization of lumped thermal dynamics in cylindrical lithium ion batteries for core temperature estimation and health, IEEE Trans. Control Sys. Technol. (accepted upon minor revision).

21 Smith K., Kim G.H., Darcy E., Pesaran A. (2009) Ther$\mathrm{mal} /$ electrical modeling for abuse-tolerant design of lithium ion modules, Int. J. Energy Res. 34, 204-215.

Final manuscript received in August 2012

Published online in March 2013 